\title{
LEGITIMANDO LA DOMINACIÓN EN LA CUENCA DEL SIGLO XV: LA TRANSFORMACIÓN DE LOS INTERESES PARTICULARES A TRAVÉS DE LA DEFINICIÓN DEL BIEN COMÚN
}

\author{
José Antonio Jara Fuente ${ }^{1,2}$ \\ Universidad de Castilla-La Mancha
}

\section{RESUMEN}

En la Edad Media (quizás habría que añadir que lo mismo que en cualquier otra época), las políticas de comunidad no fueron ni exclusiva ni esencialmente el producto de la acción directa de los dominados sino la respuesta de los dominantes a la discusión de las posiciones privilegiadas de poder que ocupaban. Evidentemente, con esta afirmación no se pretende negar la capacidad de acción de los dominados sino poner de manifiesto la implicación, y las causas de esta implicación, de los dominantes en un marco político de actuación tipo «bien común». Así, abrazar políticas de comunidad o de bien común fue, para los dominantes, una estrategia más en el proceso de consolidación tanto de la dominación en general como de su específica participación en ella.

En este trabajo, me centraré en el análisis del modo en el que el corazón de la clase dominante de Cuenca, los regidores, auspició actuaciones políticas de «bien común», transformando así la percepción que de su gestión (política y de poder) podía tener el conjunto de la comunidad.

1 Doctor en Historia Medieval. Profesor Contratado Doctor Historia Medieval. Facultad de Ciencias de la Educación y Humanidades. Universidad de Castilla-La Mancha. 16071. Cuenca. C.e.: JoseAntonio.Jara@uclm.es.

2 Este estudio se ha realizado en el marco del proyecto de investigación Fundamentos de identidad política: la construcción de identidades politicas urbanas en la Península Ibérica en el tránsito a la modernidad, concedido por el Ministerio de Ciencia e Innovación (HAR2009-08946), y dirigido por la Dra. Yolanda Guerrero Navarrete desde la Universidad Autónoma de Madrid. 
Palabras clave: Corona de Castilla. Cuenca. Siglo XV. Clase dominante. Comunidad. Bien común.

\begin{abstract}
In the Middle Ages, community politics were neither the exclusive nor sole product of the subjugated's direct action but the dominants' answer to discussion of the privileged power positions they occupied (in fact, this can be also affirmed of any other period not only of the Middle Ages). Evidently, this statement does not pretend to deny the subjugated's capacity of action but to underline the dominants' involvement, and the causes of this involvement, in a political action framework of the type «common good». Thus, for the dominants embracing community politics or common good politics was another strategy in the process of consolidating both domination itself and their specific participation in it.

In this sense, this study will focus on the way in which Cuenca's dominant class core, that is the regidores, sponsored «common good» political actions, transforming in this manner the perception that about their management (of urban politics and power) had the rest of the urban society.
\end{abstract}

Keywords: Crown of Castile. Cuenca. Fifteenth century. Ruling class. Community. Common good.

\title{
I. INTRODUCCIÓN
}

Uno de los lugares comunes transitados con mayor comodidad por la historiografía urbana peninsular se centra en la definición en términos oligárquicos de la actuación política, intereses y objetivos particulares, y también públicos, perseguidos por los integrantes de los linajes regimentales. Éstos y especialmente su personal regimental habrían asumido la dominación en sus respectivos centros urbanos en clave de satisfacción de sus solas necesidades, sin otro referente «público» que el mantenimiento de un razonable nivel de paz en el interior de la ciudad o villa, que les permitiera disfrutar sin excesivas contestaciones de los beneficios derivados de su posición en el seno de la cúpula del poder urbano. Para algunos concejos, si no para demasiados, se discute incluso si este colectivo actuó alguna vez como grupo cohesionado o simplemente persiguió sus propias utilidades singulares (linajísticas).

Es evidente que las diferentes estructuras de poder que organizaban la dominación en cada ciudad y villa, afectaron al modo en el que los dominantes (y también los dominados) pudieron y supieron posicionarse y actuar en ese espacio de gestión del poder. Desde luego, en el caso castellano, un modelo de cabil- 
do de nobles linajes, como los que vemos actuar en grandes concejos como Valladolid, Soria o Segovia, no proporciona a priori el mismo espacio de acción ni probablemente los mismos instrumentos de intervención política que podemos encontrar en concejos como Cuenca, donde la organización de la dominación no acabó de cuajar en torno a la línea de tensión linajes nobles-control del poder urbano. Pero no es menos cierto que incluso en ciudades y villas donde se ensayó aquel modelo «menos participado» de gobierno urbano, la dominación no podía consistir única y exclusivamente en un ejercicio abusivo, egoísta y oligárquico del poder; no a menos que se deseara abocar el concreto sistema urbano a un modelo de dominación en tensión, o más bien sobretensión, permanente y a un no menos constante y virulento conflicto social que habría reducido las posibilidades de aprovechamiento del sistema por los dominantes, al menos en el corto si no igualmente en el medio plazo. La «rapacidad» de los dominantes habría conducido a la contestación violenta de su posición privilegiada y, acaso, a la pérdida de ésta ${ }^{3}$.

Sin embargo, como Alain Guerreau se encargó de recordarnos en su momento, ni la dominación fue necesariamente un equivalente de opresión ni los dominantes pueden ser, así mismo necesariamente, concebidos como pequeños déspotas en persecución de su único beneficio ${ }^{4}$. Es cierto que el disfrute pacífico de sus posiciones de poder en el marco urbano dependió de su habilidad para posicionarse en otros espacios (sistemas) capaces de influir positivamente en el urbano; sus contactos con la monarquía y con importantes representantes de la alta, y en ocasiones mediana, nobleza supusieron un importante apoyo a sus aspiraciones de dominio en la ciudad o villa. Pero también lo es que esa «pacífica posesión» de la dominación dependió en muy gran medida de su capacidad de comunicación con sus respectivas sociedades urbanas. Una comunicación bidireccional, en la que una parte, más o menos significativa, de los dominados pudo ser llamada a participar en áreas, generalmente menores, de la dominación, y en la que los dominantes hubieron de asumir algunos de los objetivos, intereses materiales y referentes intelectuales (acerca de la dominación) de los propios dominados. De este modo, se propició la reducción de

3 Martínez Moro entiende así el problema planteado por los conflictos políticos en el mundo urbano castellano de la segunda mitad del siglo XV, al afirmar que las Cortes de Toledo de 1480 no deben entenderse como una oposición frontal a la actuación de los privilegiados sino como «el medio tanto de atajar una vía conducente a la desorganización social, como de evitar las colisiones de intereses que la rapacidad de los poderosos estaba a punto de crear entre ellos mismos». Vid MARTíNEZ MORO, J., La tierra en la comunidad de Segovia. Un proyecto señorial urbano (1088-1500), Universidad de Valladolid, 1985, pp. 83-84.

4 GUERREAU, A., El feudalismo. Un horizonte teórico, Crítica, Barcelona, 1984 (París, 1980), p. 203. 
la tensión social hasta niveles tolerables, así como una redefinición de la dominación, transformándose la percepción negativa de la acción de gobierno de los dominantes en un modelo de acción relativamente participada y ajustada a principios de bien comunitario 5 .

Es así que la paz social descansó en las ciudades y villas castellanas no en la capacidad de imposición de un concreto modelo de dominación (o no sólo en ello) sino en la habilidad mostrada por los dominantes para incorporar a grupos, intereses, aspiraciones y formulaciones políticas de los dominados a la propia dominación.

Unos mecanismos que, en ocasiones, constituyeron esencialmente procedimientos discursivos dotados de un escaso fundamento práctico. No obstante, la misma existencia de consecuencias materiales, por mínimas que fueran, y la insistencia en ese tipo de discurso, así como el ser contextualizado en el marco de unas acciones generales de gobierno fundamentalmente no anticomunitarias, facilitó su asimilación por los dominados y la consiguiente y positiva categorización de los dominantes. Precisamente, en este trabajo analizaré cómo el corazón de la dominación en Cuenca, integrada por el colectivo de linajes regimentales y específicamente los regidores, supo posicionarse intelectual y materialmente ante la noción «bien común» con el fin de construir un discurso comunitario cuya lectura resultara sencilla para todos los habitantes de la ciudad (y la tierra de su jurisdicción, aunque aquí me centraré en la primera parte de esa ecuación jurisdiccional). Un discurso comunitario basado en referentes teóricos afines a las aspiraciones de los dominados pero también en prácticas políticas dirigidas a la satisfacción de las necesidades de la comunidad urbana en su conjunto. A través de estos procedimientos de actuación, la acción de gobierno obtenía la necesaria sanción positiva, la legitimación acordada (fundamentalmente de modo tácito) por los dominados y, con ella, la legitimación de las posiciones de poder disfrutadas en el interior del sistema urbano «Cuenca».

5 Para un contexto similar, Daniel Hickey propone centrarse no sólo en los planteamientos ideológicos que, de manera apriorística, dan vida a este colectivo sino especialmente en un análisis «à partir de leurs actions sociales et symboliques dans le cadre (des) communautés où ils sont vécu, et non à partir d'une grille idéologique». Vid «Les mécanismes de la stratégie sociale. Bienfaiteurs et administrateurs des hôpitaux locaux en France aux XVIIe et XVIII siècles», en GUTTON, J-P. (dir.), Les administrateurs d'hôpitaux dans la France de l'Ancien Régime, PUL, Lyon, 1999, pp. 19-41, citado en CROQ, L., «Essai pour la construction de la notabilité comme paradigme sociopolitique», en LAURENCE, J-M. (ed.), La notabilité urbaine, Xe-XVIIle siècles, Actes de la Table Ronde organisé à la Maison de la Recherche en Science Sociales, CNRS-Université de Caen Basse-Normandie, Caen, 2007, pp. 23-38. 


\section{LA PRODUCCIÓN DE UN SENTIDO DE «COMUNIDAD DEL BIEN COMÚN»: EQUILIBRIOS (INTELECTUALES) ENTRE DOMINACIÓN Y COMUNIDAD}

El 20 de Marzo de 1469, Honorato de Mendoza, hijo del guarda mayor de la ciudad de Cuenca y señor de Cañete, Juan Hurtado de Mendoza, comparecía ante el concejo para jurar su cargo de procurador a Cortes por Cuen$\mathrm{ca}^{6}$. En esa ceremonia de juramento, el Mendoza asumía ante la ciudad un «programa de trece puntos» en el que se comprometía a guardar el servicio del rey y la ciudad, trabajar por mantener el concejo dentro del realengo, y asegurarse de que se respetaran los privilegios de la urbe y aquellos que disfrutaban algunos de sus vecinos (sobre todo en cuanto a la libre posesión de sus maravedíes de juro y otras mercedes) $)^{7}$. Buena parte del programa obedecía a fórmulas y objetivos de carácter general, vinculados a cuestiones tales como el servicio al rey y a la ciudad, el mantenimiento de la Casa de la Moneda en Cuenca, y la confirmación del mercado franco concedido a la ciudad así como de las otras mercedes y privilegios que poseía el concejo. Pero un pequeño número de ellas, altamente significativas, adquiría su lógica en el marco de la situación de guerra civil por la que transitaba el reino. Así, Honorato de Mendoza debía esforzarse por obtener del rey que no se levantara el destierro de quienes habían actuado en su deservicio (un destierro que no necesariamente tenía que haber sido acordado por el propio monarca, por lo que la ciudad lo que venía a solicitar era, en parte, la sanción de las posibles penas de destierro impuestas, o por imponer, por el concejo $^{8}$, asegurarse de obtener el beneplácito regio por las acciones em-

6 AMC (Archivo Municipal de Cuenca), LLAA (Libros de Actas), leg. (legajo) 198, exp. (expediente) 3, fols. 22r-v.

7 Estrictamente hablando, ni el concejo ni Honorato de Mendoza produjeron un documento formalmente organizado en torno a «trece puntos». El acto de juramento, como otros celebrados en la propia Cuenca y en otros concejos castellanos, simplemente relacionaba, mediante enunciados sucesivos, las cuestiones que interesaban a la ciudad y el procurador debía defender ante el rey. Los «trece puntos» surgen de y se corresponden con ese enunciado sucesivo de cuestiones.

8 La documentación abunda en referencias a los desterrados, sobre todo en tiempos de guerra civil, cuando las autoridades concejiles o incluso el conjunto de la comunidad política urbana se juramentan para impedir su entrada en la ciudad. En los años que rodean al documento que estamos analizando, sucede el 28 de Noviembre de 1468 y el 26 de Febrero, 8 de Abril y 24 de Abril de 1469. Cfr. AMC, LLAA, leg. 197, exp. 1, fols. 24v-25r; leg. 198, exp. 2, fols. 58v-60r; y leg. 198, exp. 3, fols. 13r y 33r.

Estas penas de destierro tienen, desde luego, una componente política de primer nivel, que afecta principalmente al servicio debido al rey, descansando entonces generalmente la condena en manos del monarca (lo que no significa que no haya habido mediación 
prendidas para defender la ciudad de los rebeldes (lo que incluía la condonación de los maravedíes tomados por el concejo de la fiscalidad regia con el fin de contribuir a satisfacer los gastos generados por dichas medidas $)^{9} \mathrm{y}$, finalmente, defender el modelo político-constitucional que daba vida al urbanismo castellano, el regimiento. Y no se trataba de una pequeña defensa, en modo alguno.

Efectivamente, como quiera que -según se recoge en el documento de juramento- en muchas ciudades, villas y lugares del reino se habían levantado gentes y se anda ligando los pueblos contra el regimiento e regidores de las tales çibdades e villas, perturbando los ofiçios a los regidores e fasiéndose ellos regidores e ponyendo diputados syn mandado del dicho sennor rey, Honorato de Mendoza debía instar la redacción de una ley, general para el reino o al menos específica para Cuenca, disponiendo que qualquier persona que lo semejante mouiere contra el dicho regimiento e regidores, que pierda los bienes e muera por ello ${ }^{10}$. Con esta cuestión, los

urbana en la toma de decisión regia); pero también obedecen a aspectos políticos de segundo nivel, ligados al servicio de la comunidad urbana, siendo las conductas anticomunitarias objeto, en este caso, de condena por las autoridades concejiles. Es lo que sucede, por ejemplo, el 8 de Abril de 1468, al penarse con destierro a quienes no acudan a prestar su servicio de ronda y vela; el 25 de Abril de 1468, al establecerse que ningún caballero acompañe a los caballeros de la sierra en su función de guardar los términos de ciudad y tierra; el 7 de Octubre de 1468, cuando el concejo pena con un destierro de la ciudad por tres meses a quien resulte condenado en tres ocasiones por infringir la ordenanza dictada sobre el portar armas; o, en fin, en Septiembre de 1482, al introducirse el destierro como sanción a los mercaderes, tintoreros y perailes que conculquen la ordenanza dictada sobre la perailía. Cfr. AMC, LLAA, leg. 198, exp. 2, fols. 18v-19r, 24r y 32r; y leg. 204, exp. 1, fols. 25r-v.

9 Así, por ejemplo, entre las condiciones que impuso el concejo en Noviembre de 1467 a Juan de Sampedro, facedor y recaudador de las alcabalas y tercias del obispado de Cuenca, para recibirle en dicha condición, figuró el que se comprometiera a no reclamar los maravedíes tomados de dichas rentas en 1466 y 1467 para pagar el sueldo de las gentes que había en la ciudad en servicio del rey y defensa de Cuenca y su tierra. El recaudador se comprometió a ello y fue recibido el 9 de Noviembre. Cfr. AMC, LLAA, leg. 198, exp. 1, fols. 92v-93r.

El 17 de Febrero de 1470, el concejo ordenaba a Álvaro Gallego, procurador síndico de la ciudad, tomar los maravedíes, que en su momento se le indicaran, de las alcabalas y tercias; en esta ocasión, la medida no contó con el acuerdo unánime del concejo pues consta que, unos días más tarde, el regidor Juan Álvarez de Toledo y el alcalde mayor Juan de la Bachillera manifestaron su oposición a la toma. Cfr. AMC, LLAA, leg. 198, exp. 3 , fols. 159r-v.

${ }^{10}$ La propuesta del concejo no era tan descabellada como a primera vista pudiera parecer pues a lo largo del siglo este tipo de circunstancias había constituido una de las preocupaciones de los procuradores a Cortes, como se comprueba en las Cortes de Ocaña de 1422 (petición 16), de Palenzuela de 1425 (petición 14), de Zamora de 1432 (petición 33), de Córdoba de 1455 (petición 15) y de Santa María de Nieva de 1473 (petición 1). Cfr. Cortes de los antiguos reinos de León y de Castilla, vol. III, Real Academia de la Historia, Madrid, 1866. 
regidores daban por cerrado el conjunto de medidas que debía jurar el hijo del guarda mayor. Y el hecho de figurar en último lugar no debe conducir a engaño sobre la importancia que aquellos asignaban a la preservación de su estatus y poder en la ciudad. En este sentido, si la crudeza del planteamiento de esta medida no resultara suficientemente ilustrativa del interés mostrado por el equipo regimental en su propia preservación, el hecho de que el documento dedique otros dos apartados a la protección-defensa de sus posiciones confirma ese superior interés.

Así, antes y por encima de todo, lo que importaba a los regidores era la aseguración de las privilegiadas posiciones de poder que ocupaban en el interior del sistema urbano; como no podía ser de otra manera, casi habría que añadir. Para ello, estaban dispuestos a promover activos y agresivos mecanismos de sanción, que penalizaban no sólo al sujeto implicado en la conducta ilícita sino también al conjunto de su familia o linaje, al preverse, como castigo de dichas conductas, no sólo la imposición de la pena de muerte sino también la confiscación de bienes ${ }^{11}$. Evidentemente, mediante este procedimiento se pretendía ligar la seguridad de esa «pequeña comunidad» que eran la familia o el linaje a las efectivas acciones políticas emprendidas por las singularidades (individuos) que la integraban. En cierta manera, este tipo de medidas venía a jugar con un concepto reducido de bien común (en tanto que afectaba a unidades menores de la comunidad política urbana, como la familia o el linaje); un concepto reducido pero altamente operativo, en la medida en que hacía depender el bien común de la unidad social básica de segundo orden (el individuo) del bien común (definido como superior) de la unidad social básica de primer orden (la familia o linaje).

De esta manera, el regimiento imponía con firmeza la lógica última de la dominación: la preservación del propio espacio de poder y el poder mismo frente a los posibles adversarios que pudieran discutir la primacía política de los regidores. No obstante, la medida así promovida generaba una percepción (correcta) de la verticalidad de las relaciones de poder en el interior del sistema urbano no exenta de (¿mínimas?) contradicciones o, mediante una expresión probablemente más acertada, correcciones políticas. Por un lado, convenía hacer presente la materialidad de la dominación, al menos ocasionalmente, para sancionar el modelo de dominación, su percepción y asimilación por el conjunto de la sociedad,

${ }^{11}$ Desde luego, no se trata de una medida original del concejo conquense pues ha formado y forma parte del arsenal de respuestas coercitivas a disposición de los dominantes (urbanos o no) en todo tiempo y lugar. Cuenca sólo aprovechaba en su propio interés este tipo de instrumentos.

Un buen análisis del uso de este tipo de medidas se encuentra en RICCIARDELLI, F., The Politics of Exclusion in Early Renaissance Florence, Brepols, Turnhout, 2007. 
así como su funcionamiento consciente y especialmente latente (integrado en el inconsciente colectivo urbano). Sin embargo, por otro, uno de los éxitos de la dominación en Cuenca venía dado por la capacidad mostrada por el regimiento para integrar a otros segmentos (dominantes y dominados) de la estructura social en escalones diversos del proceso político-decisional y del sistema de disfrute de los beneficios de la dominación ${ }^{12}$; una integración fundada, por una parte, en un acceso efectivo a dichos espacios de poder y, por otra, en la construcción de una determinada percepción de la acción de los dominantes, orientada a la satisfacción social del bien común colectivo. En este caso, el enunciado final del «programa de trece puntos» aparentemente satisfacía la primera necesidad de materialización de la dominación pero contradecía su segundo objetivo de colectivización de ésta ${ }^{13}$. Aunque sólo aparentemente, al menos en el plano ideológico o intelectual.

A través de tres procedimientos, incorporados al programa y al juramento, los regidores procuraron transformar la rigidez y particularismo de la defensa de su dominación, ligando en cierta medida ésta, las posiciones que ocupaban en el interior del sistema urbano y el poder que ejercían a la promoción de los intereses de otros sectores de la comunidad política urbana y de ésta en su conjunto y, en última instancia, a la defensa de la integridad política de la comunidad.

En este sentido, resulta interesante observar cómo se abre el documento con la llamada a dos acciones de igual naturaleza aunque diverso recipiendario. Así, se requiere a Honorato de Mendoza para que se comprometa a guardar, en primer lugar, el servicio del rey y, en segundo lugar, el servicio del obispo de Cuenca, don Lope de Barrientos (principal valedor de Enrique IV en el área y, por extensión, de las libertades del propio concejo), así como el servicio de la ciudad y su tierra y, así mismo, el servicio del regimiento.

${ }^{12}$ Me he ocupado de ello en Concejo, poder y élites. La clase dominante de Cuenca en el siglo XV, CSIC, Madrid, 2000; «Posiciones de clase y sistemas de poder: vinculaciones y contradicciones en la construcción del 'común de pecheros' en la Baja Edad Media», en IGLESIA DUARTE, J.I. (ed.), Los espacios de poder en la España medieval (XII Semana de Estudios Medievales, Nájera 2001), Instituto de Estudios Riojanos, Logroño, 2002, pp. 511-532; «The Importance of Being Earnest: Urban Elites and the Distribution of Power in Castilian Towns in the Late Middle Ages», en ALFONSO ANTÓN, I., KENNEDY, H. y ESCALONA MONGE, J. (eds.), Building Legitimacy. Political Discourses and Forms of Legitimation in Medieval Societies, Brill, Leiden-Boston, 2004, pp. 139-175; y «Attributing Social Fields and Satisfying Social Expectations: the Urban System as a Circuit of Power Structuring Relations (Castile in the Fifteenth-Century)», en ASENJO GONZÁLEZ, M. (ed.), Oligarchy and Patronage in Late Medieval Spanish Urban Society, Brepols, Turnhout, 2009, pp. 91-115.

${ }^{13}$ Sobre la contradicción implícita en este tipo de planteamientos, véase CROZIER, M. y FRIEDBERG, E., Lacteur et le système. Les contraintes de l'action collective, Éditions du Seuil, Lonrai, 1981 (1ª 1977), p. 93. 


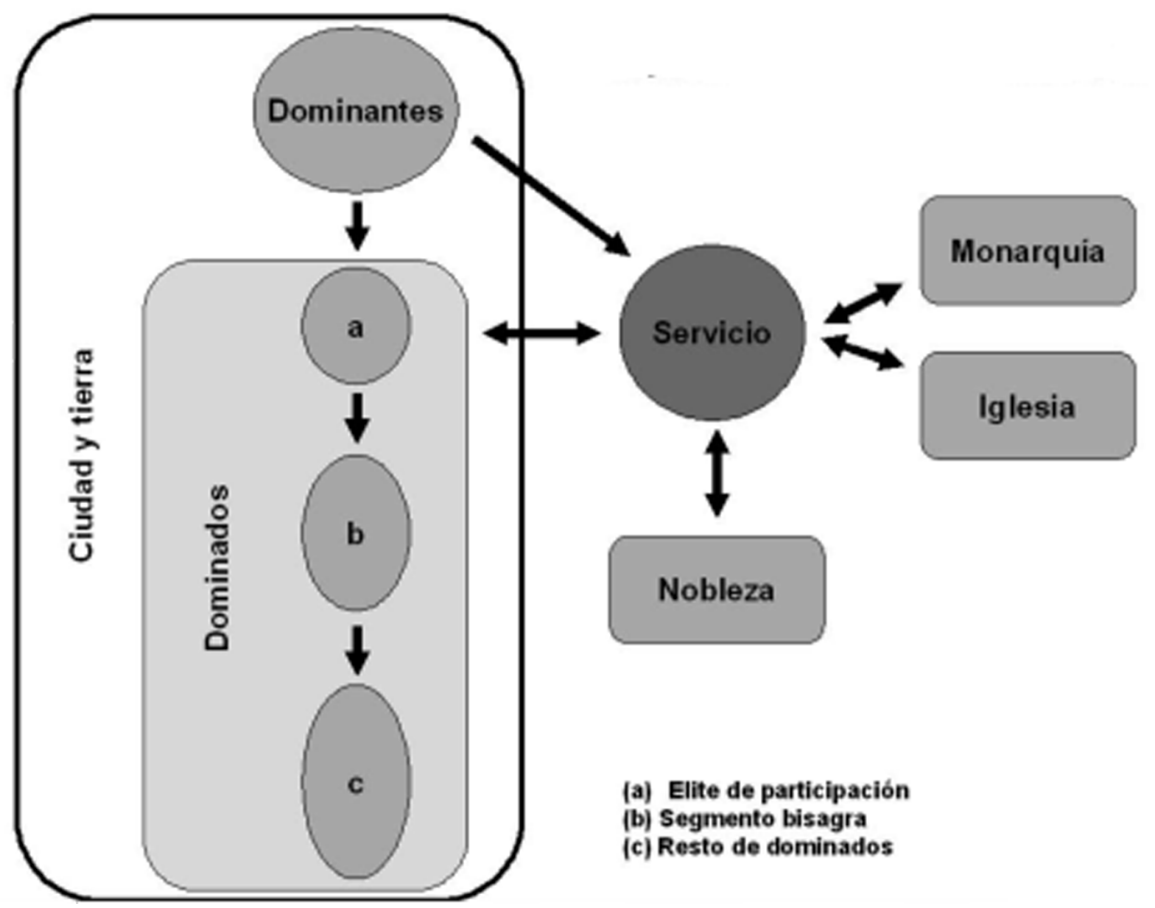

Gráfico 1. Procedimientos de colectivización de la dominación

Mediante esta encadenación de cláusulas del juramento, los regidores alcanzan a elaborar una cadena de relaciones conceptuales en la que, alrededor de la noción «servicio», ligan la percepción de su posición políticoconstitucional a la de la propia ciudad y tierra, pues la exigencia al Mendoza de que guarde el servicio de ciudad y tierra, como objeto autónomo de su acción servicial y, por tanto, esencialmente diferente del regimiento, conlleva la propia implicación servicial del regimiento para con la ciudad y tierra, cuyo procomunal persigue de este modo. Es de esta forma que la noción «servicio» muestra su operatividad, al presentarse/utilizarse, de un lado, como elemento integrador de los diferentes intereses particulares en juego: servicio al rey, servicio a la Iglesia (o quizás resultaría más adecuado, en esta ocasión, tener presente la especial relación construida con don Lope de Barrientos más que con el sistema «Iglesia» en sentido estricto), servicio a la ciudad y tierra, y servicio al mismo regimiento; y, de otro, al permitir la reducción de algunos intereses particulares (los regimentales) en otros de naturaleza colectiva/comunitaria (los del conjunto, regidores incluidos, de 
ciudad y tierra) ${ }^{14}$. Igualmente, mediante la incorporación (no del todo voluntaria para el concejo) de Honorato de Mendoza al servicio de la procuración a Cortes, se insertaba también a un sector de la nobleza (el que se hallaba en servicio del rey y afecto, al menos coyunturalmente, a la ciudad) a este encadenamiento de relaciones serviciales, proporcionándose al conjunto de la comunidad política urbana una cierta sensación de seguridad en la defensa (por el rey, el obispo, los Mendoza, y los regidores) de sus intereses colectivos (en la medida en que toda relación servicial tiene un carácter biunívoco y el servicio es objeto de la correspondiente satisfacción, con independencia de la naturaleza de ésta) ${ }^{15}$.

De este modo, en esta ocasión como en muchas otras, los regidores construyen la percepción de un espacio unificado de relación política con el conjunto de ciudad y tierra; un espacio colectivizado por su acción «servicial» de gobierno. Sobre ello abunda el segundo de los elementos que se pone en juego, la persecución de objetivos de pro común, como son los ya enunciados de preservación de la Casa de la Moneda (de los intereses económicos generales de la ciudad y particulares de los monederos) o la confirmación de la concesión de un mercado franco a la urbe. Se trata de objetivos que no afectan directamente a los intereses particulares de los linajes regimentales, y que ilustran el compromiso de los regidores con la defensa de los intereses colectivos.

La colectivización de estos intereses particulares regimentales no tiene mejor expresión que el último instrumento a través del cual construyen esta percepción de acción colectiva. La cláusula duodécima del juramento requiere a Honorato de Mendoza que procure ante el rey la revocación de los oficios de voz y voto y las cartas expectativa de regimiento, porque en aver grand número de semejantes ofiçios viene

${ }^{14}$ Sobre la operatividad de la noción «servicio», véanse los trabajos de GIBERT Y SÁNCHEZ DE LA VEGA, R., El concejo de Madrid, I. Su organización en los siglos XII al XV, Instituto de Estudios de Administración Local, Madrid, 1949, p. 105; ASENJO GONZÁLEZ, M., «Clientélisme et ascension sociale à la Ségovie à la fin du moyen-âge», en Journal of Medieval History, 12 (1986), pp. 167-182; HORROX, R., «Service», en Horrox, R. (ed.), Fifteenth-Century Attitudes: Perceptions of Society in Late Medieval England, Cambridge University Press, Cambridge, 1994, pp. 61-78; CURRY, A. y MATTHEW, E. (eds.), Concepts and patterns of service in the later Middle Ages, The Boydell Press, Woodbridge, 2000; LIDDY, Ch.D. War, Politics and Finance in Late Medieval English Towns. Bristol, York and the Crown, 1350-1400, The Royal Historical Society, Trowbridge, 2005, pp. 1-3; HORROX, R., Richard III: a Study of Service, Cambridge University Press, Cambridge, 1989, p. 5; PALLISER, D.M. Towns and Local Communities in Medieval and Early Modern England, Ashgate, Aldershot-Burlington, 2006, pp. 127-145; y JARA FUENTE, J.A., «Commo cunple a seruiçio de su rey e sennor natural e al procomún de la su tierra e de los vesinos e moradores de ella. La noción de 'servicio público' como seña de identidad política comunitaria en la Castilla urbana del siglo XV», en monográfico Cultura, lenguaje y prácticas políticas en las sociedades medievales, dirigido por ALFONSO ANTÓN, I., e-Spania, 4 (2008), pp. 1-30, URL: http://e-spania.revues. org/document 1223.html.

${ }^{15}$ HORROX, R., Richard III: a Study of Service, Cambridge University Press, Cambridge, 1989, pp. 1-5. 
deserviçio a su altesa e danno a la dicha çibdad. Ahora, mediante un procedimiento discursivo impecable, se oscurecen, hasta suprimirlos, los intereses particulares de los regidores, la integridad de cuyo cuerpo político descansa en el control que pueden ejercer sobre el acceso al regimiento ${ }^{16}$. Simultáneamente, se recupera la noción «servicio» para evaluar el alcance (negativo) de voces y cartas; la conclusión es clara: deservicio al rey y daño (deservicio) a la ciudad. Así, una vez más, mediante estas formulaciones del servicio los regidores transforman (o pretenden transformar) la percepción de su acción de gobierno, mutando lo particular en comunitario.

\section{LA «SIGNIFICACIÓN COMPARTIDA DE LA COMUNIDAD»: LA EXPRESIÓN (CASUÍSTICA) DEL BIEN COMÚN}

Ahora bien, en el marco de simples casos aislados de acciones de gobierno con sentido comunitario, ni los regidores podían aspirar a hacer (ni entera ni inmediatamente) inteligible para el conjunto de la comunidad este tipo de acciones, ni la comunidad disponía de los referentes intelectuales necesarios para «leerlas» $\mathrm{y}$ «traducir» su lenguaje en términos de políticas comunitarias claras y precisas. Puesto que «bien común» y «comunidad» eran nociones más sentidas-intuidas que definidas y explicitadas en toda su extensión y profundidad, su expresión suponía la operación de las relaciones políticas comunitarias dentro de unos marcos de referencia preexistentes y manipulables sólo hasta cierto punto pues, pese a la indefinición material del conjunto de sus elementos, rasgos y naturaleza, existía una extendida percepción básica de lo que aquellas nociones debían

\footnotetext{
${ }^{16}$ Sobre el particular véanse JARA FUENTE, Concejo, poder y élites, op. cit.; GUERRERO NAVARRETE, Y. y SÁNCHEZ BENITO, J.M., Cuenca en la Baja Edad Media: Un sistema de poder, Diputación de Cuenca, Cuenca, 1994, p. 130; de los mismos autores, «Del concejo medieval a la ciudad moderna. El papel de las cartas expectativa de oficios ciudadanos en la transformación de los municipios castellanos bajomedievales: Burgos y Cuenca», en Actas de las III Jornadas Hispano-Portuguesas de Historia Medieval, La Península Ibérica en la Era de los Descubrimientos (1391-1492), 2 vols., Sevilla, del 25 al 30 de Noviembre de 1991, Sevilla, 1997, II, pp. 1013-1024; y GUERRERO NAVARRETE, Y., «Elites urbanas en el siglo XV: Burgos y Cuenca», en Història Medieval, 9 (1998), pp. 81-104.

Para los regidores castellanos, el control sobre el acceso al regimiento y la preservación de una dimensión razonable (número de miembros) para esta institución, constituyeron una de las principales líneas de acción-negociación con la monarquía, como muestra su continua presencia en las reuniones de Cortes. Así, peticiones similares a la que examinamos, constan en las Cortes de Madrid de 1419 (petición 8), Valladolid de 1420 (petición 1), Palenzuela de 1425 (peticiones 3 y 26), Madrid de 1433 (petición 2), Madrid de 1435 (petición 2), Olmedo de 1445 (Ordenamiento contra el acrecentamiento de oficios), Valladolid de 1447 (petición 51), Valladolid de 1451 (petición 13), Burgos de 1453 (petición 29), Toledo de 1462 (petición 6), y Ocaña de 1469 (petición 7). Cfr. Cortes de los antiguos reinos de León y de Castilla, op. cit.
} 
significar ${ }^{17}$. Así, la generación en el seno de la comunidad urbana de una percepción «correcta» (en términos comunitarios) de la acción de gobierno no descansaba únicamente en la construcción discursiva de dicha acción de acuerdo con las imágenes y procedimientos lingüísticos objeto del marco de referencia «bien común», sino también y especialmente en la más o menos permanente operación de dichos elementos y marco, de modo que el engranaje de la comunicación regimiento (dominantes)-dominados no sólo permaneciera bien engrasado sino que facilitara la consecución entre el conjunto de la sociedad urbana de un cierto «hábito de lectura» de la acción de gobierno en términos de política comunitaria.

Es lo que, para otra época y otras coordenadas político-sociales, ha puesto de manifiesto George Lakoff. Según este especialista en lingüística cognitiva, el cerebro y sus operaciones se organizan, en lo que a esta discusión concierne, alrededor de marcos conceptuales, marcos de referencia que forman parte del inconsciente colectivo y disciplinan las relaciones lingüísticas (comunicativas) al reconducir los modos de producción de significante al contenido de dichos marcos (lo cual no significa que los marcos resulten inmutables pues son susceptibles de transformación mediante aprendizaje de nuevos marcos, aunque éste resulta un proceso generalmente lento). En este contexto, los procesos de «enmarcado» suponen la construcción o reconstrucción de la acción social en los términos lingüístico-intelectuales del marco de referencia escogido, lo que resulta fundamental sobre todo en el caso de aquellas acciones cuyo contenido real puede llegar a ser o directamente es contradictorio con los ideales del marco en cuestión. En estos casos, la inserción de acciones políticas en marcos conceptuales contradictorios se verifica a través de un procedimiento de manipulación del lenguaje tanto más sencillo de ejecutar y tanto más exitoso en su relación comunicativa cuanto más verosímilmente se adecúa a las constricciones intelectuales del marco y mayor es la ocurrencia de la producción de estas acciones ${ }^{18}$.

Esta es la razón que se encuentra en la base de la prácticamente continua actuación de las autoridades urbanas en el sentido de vincular sus decisiones a la persecución de políticas de bien común. La legitimación y pacífico disfrute de su posición privilegiada en el sistema de dominación dependía de la percepción

${ }^{17}$ De esto me he ocupado en «Con mucha afecçión e buena voluntad por seruir a bien público: la noción 'bien común' en perspectiva urbana. Cuenca en el siglo XV», monográfico dirigido por J.M. MONSALVO ANTÓN, Studia Historica. Historia Medieval, en prensa.

${ }^{18}$ LAKOFF, G. No pienses en un elefante. Lenguaje y debate político, Universidad Complutense, Madrid, 2007 (Don't Think of an Elephant! Know Your Values and Frame the Debate, Chelsea Green Publishing Company, White River Junction (Vermont, EE.UU.), 2004), especialmente pp. 17-24, 110 y 147. 
que el conjunto de la comunidad tuviera de las acciones específicas de gobierno; una percepción que atendía no sólo a la consideración que estas acciones, tomadas aisladamente, podían merecer sino especialmente a la comprensión de su significado como un todo, a la consideración de lo que la (podemos denominar como) acción general de gobierno representaba (en términos tendenciales, en pro o en contra del procomunal urbano).

Por ello, la documentación se halla transida de acuerdos de muy diversa naturaleza, adoptados teniendo siempre presente la necesidad de ligarlos, de una u otra manera, al procomunal. Así por ejemplo, el 7 de Octubre de 1482 se prohibía la vendimia hasta el día de San Lucas (18 de Octubre), justificándose la medida por ser commo es bien general de todos los que tienen vinnas e han de vendimiar; el 22 de Junio de 1465, en respuesta a la solicitud de un vecino del concejo aldeano de Jábaga para que se le asignara un solar para edificar una casa en dicho término, Cuenca aprobaba la petición pues es manifiesto ser en utilidad e provecho del dicho lugar Jábaga e de acreçentar e mejor façer en él poblaçión e acreçentamiento; el Lunes 12 de Agosto de 1476 los regidores acordaban no dar licencia a nadie para vender cosa alguna hasta el Viernes siguiente, salvo las licencias que pudieran otorgar los regidores con cargo, pues que conosçidamente lo tal redunda en grand bien de la república; y, en fin, el 3 de Octubre de 1436, reunidos para nombrar al mayordomo y receptor del ejercicio 1436/1437, designaban nuevamente al receptor saliente Ferrand López de Requena, porque entendían que era conplidero a seruiçio del dicho sennor [rey e] al pro común de la dicha çibdat e su tierra ${ }^{19}$. Incluso cuando se trata de terceros agentes, que actúan en el interior del sistema urbano, la referencia a este marco conceptual es también una cuestión prácticamente obligada. Así sucede el 7 de Junio de 1483, cuando García de la Cuadra, regidor de Valladolid y enviado por los reyes ante el concejo, propone una serie de medidas en favor de la justiçia e bien de la república; o dos meses antes, el 10 de Mayo, cuando el concejo pide a los reyes que, si finalmente designan un corregidor para la ciudad, lo sea sólo para este concejo y no simultáneamente para otros, porque asy cumple a su serviçio e bien público de la dicha çibdad e su tierra ${ }^{20}$.

Mediante este tipo de prácticas discursivas, los regidores promovieron una legitimación de la dominación basada tanto en la persecución de objetivos de bien común como, consiguientemente, en la participación en un proyecto político y vital de carácter comunitario que incorporaba al conjunto de vecinos de la ciudad. Unas prácticas discursivas que descansaban, de un lado, en una acción

${ }^{19}$ AMC, LLAA, leg. 204, exp. 1, fol. 54r; leg. 197, exp. 4, fol. 54v; leg. 200, exp. 2, fols. 4r-v; y leg. 189, exp. 1, fol. 13r.

20 AMC, LLAA, leg. 205, exp. 2, fols. 16r y 34r. 
de gobierno cuya orientación «comunitaria» se asumía con carácter voluntario $\mathrm{y}$, de otro, en un sentido de comunidad participada que derivaba de la implicación de aquellas prácticas en políticas de bien común. Mediante este procedimiento, voluntariedad y comunidad participada se presentaban como los pilares básicos sobre los que se construía la vinculación regidores-comunidad política $^{21}$. De esta manera, prácticas discursivas, marco conceptual «bien común», conducta voluntaria y sentido de participación en la comunidad venían a operar como referentes intelectuales para la percepción de la comunidad política urbana total ${ }^{22}$.

Es por ello que la continua referencia a unas prácticas o referentes teóricos de bien común no constituyen groseras inserciones políticas por parte de los regidores en su diaria gestión de gobierno, en el deseo (¿fútil?) de ocultar los posibles intereses particulares que aquéllas venían a sustentar. Si la existencia de estos intereses particulares es algo incontestable, el uso continuado de los marcos referenciales «comunidad»y «bien común» era cualquier cosa menos grosero. Efectivamente, una parte, cuantitativa y cualitativamente, significativa de las decisiones de gobierno adoptadas por los regidores ni dependía de ni atendía a la satisfacción de sus intereses, como hemos tenido ocasión de señalar más arriba; por ello, su vinculación a la persecución de políticas de procomunal era relativamente sencilla y de fácil percepción como tall ${ }^{23}$. Además, la permanente

${ }^{21}$ Sobre la operatividad de los mecanismos de actuación «voluntariedad» y «comunidad», véase VIOLA, F., Identità e comunità: Il senso morale della politica, Vita e pensiero, Milán, 1999; especialmente el capítulo primero, «Le ragioni della comunità», pp. 3-28 (originalmente «Le ragioni della comunità: il vinculo pre-politico», en VVAA, ¿Una democracia de minorías? Ciudadanía y exclusión en la democracia multicultural, UIMP, Valencia, 1997).

${ }^{22}$ En este sentido, Etienne Balibar pone de manifiesto la importancia de este tipo de mecanismos en la producción de un sentido de comunidad política, destacando el valor de la comunicación discursiva operada entre los actores sociales alrededor de dichos instrumentos. Vid BALIBAR, E., «The Nation Form: History and Ideology», en BALIBAR, E. y WALLERSTEIN, E., Race, nation, class: ambiguous identities, Verso, 1991, pp. 86-106.

${ }^{23}$ Éste es uno de los aspectos más discutidos de estas políticas, desde un punto de vista teórico. Refiriéndose a uno de los ámbitos de las políticas comunitarias, el de la producción de bienes públicos, Mancur Olson acude al principio del «propio interés racional» para explicar por qué el individuo no contribuirá al bienestar colectivo mediante su participación en la producción de bienes públicos más allá de lo que resulte necesario para alcanzar el beneficio que busca en su propio interés. Para Olson, unos índices mayores de colaboración sólo se pueden alcanzar mediante la coerción o la ejecución de programas dirigidos a la obtención de beneficios concretos (o mediante una combinación de ambas estrategias). Michael Taylor rechaza este modelo de análisis, afirmando su carácter estático y apostando por otro más dinámico, en el que las acciones que pueda emprender cada individuo dependan positivamente de las que adopten los demás. En este modelo de «cooperación condicional», un individuo puede hacer su contribución al sistema de bienes públicos siempre que otros lo hagan también (siempre que un número suficiente de otras personas lo haga 
referencia a estos marcos retroalimentaba el entero proceso de percepción de la acción de gobierno en el sentido buscado por los regidores ${ }^{24}$. Por lo mismo, el equipo regimental no desaprovechaba aquellas ocasiones en las que podía poner de manifiesto ante la comunidad política el alcance de estos compromisos político-comunitarios, al tiempo que ensayaba la operatividad de aquellos instrumentos. Es lo que sucede, por ejemplo, el 17 de Febrero de 1470, cuando, como consecuencia de las usurpaciones realizadas por el conde de Medinaceli en el sexmo de la Sierra y los gastos que ello ocasionaba a la ciudad, el concejo mandó a Sancho de Santo Domingo, vecino de Cuenca y arrendador de la sisa de la carne, que entregara inmediatamente al concejo $5.000 \mathrm{mrs}$. a cuenta de los ingresos procedentes de dicha renta. Ante su negativa, el concejo le requirió nuevamente, plegándose entonces Sancho al mandato de la ciudad, aunque manifestando que lo fasya a fuerça e que él non quería dar nin pagar los dichos çinco mill maravedies [...] que lo pedía por testimonio commo por fuerça e contra su voluntad se le fasyan pagar25. En esta ocasión, importó al regimiento recoger por extenso la oposición de Sancho de Santo Domingo pues ésta le proporcionaba claros réditos políticos ${ }^{26}$. Así, frente a una decisión adoptada en defensa de la comunidad de ciudad y tierra (ante las agresiones de un miembro de la alta nobleza del

también). Michel Crozier y Erhard Friedberg, situándose en un punto intermedio entre ambas teorías, y dentro de un análisis dedicado a las organizaciones, afirman la existencia en toda organización de unos «objetivos compartidos» que explican la puesta en ejecución de prácticas cooperativas de actuación; ahora bien, al margen de esa nómina de objetivos comunes, también reconocen la diversidad de racionalidades que animan la acción social en el seno de toda organización, negando consiguientemente la existencia de una unicidad de objetivos en su seno. Esta última aproximación al problema nos parece la más relevante para nuestro tipo de análisis.

Cfr. OLSON, M., The Logic of Collective Action: Public Goods and the Theory of Groups, Harvard University Press, Cambridge (Massachusetts)-Londres, 1971, pp. 21, 66-76 y 88-91; TAYLOR, M., Community, Anarchy and Liberty, Cambridge University Press, Cambridge, 1982, pp. 44-53; y CROZIER, M. y FRIEDBERG, E., L'acteur et le système, op. cit., pp. 91-93.

24 En este sentido, poco importaba que algunas (o muchas) decisiones no persiguieran realmente objetivos de bien común, siempre que fueran presentadas dentro de dicho marco y en el seno de un discurso coherente con éste. Como señala Lakoff, ante una contradicción entre la realidad (los hechos) y el marco de referencia, el individuo tiende a ignorar los hechos y a mantener el marco. Cfr., LAKOFF, No pienses en un elefante, op. cit., pp. 25 y 110.

${ }^{25}$ AMC, LLAA, leg. 198, exp. 3, fol. 158v.

${ }^{26}$ Si bien las actas del concejo apenas recogen el contenido textual de los debates habidos con ocasión de las sesiones de ayuntamiento y otros actos públicos registrados en ellas, no es en absoluto inhabitual que sí acojan el testimonio presentado por los oficiales del concejo o los particulares cuando interponen una queja, protesta o reclamación, como en este caso. Lo relevante de la manifestación hecha por Sancho de Santo Domingo no es su inserción en el acta del 17 de Febrero de 1470 sino la sencillez con la que su contenido podía manipularse en beneficio de la agencia regimental. 
reino), se levantaba la voluntad anticomunitaria de quien se negaba a colaborar (contra su voluntad se le fasyan pagar). Al tratarse de un miembro del laxo colectivo de quienes integraban la dominación, aunque en posiciones secundarias o más o menos excéntricas (elite de participación), la medida adoptada por los regidores, al perjudicar a uno de sus «colegas» de clase, adquiría una superior dimensión comunitaria y conducía a una percepción más favorable de su acción de gobierno y posición de poder (además, el hecho de disciplinar la voluntad anticomunitaria de un arrendador de rentas, al descansar en la imagen no precisamente positiva de este colectivo, incentivaba el tipo de percepción y discurso elaborados por los regidores).

\section{CONCLUSIONES}

En Marzo de 1420, el concejo dictaba una ordenanza sobre el arrendamiento de la renta del derecho de vender pan cocido, en cuya disposición quinta se reservaba la facultad de revocar el remate de la renta y el poder asignarla a quien estimara oportuno si ello cunple a pro común de la dicha Çibdat ${ }^{27}$. Del mismo modo a lo dispuesto el 17 de Febrero de 1470, sobre el arrendamiento de la sisa de la carne efectuado por Sancho de Santo Domingo, el concejo se reservaba el derecho de intervenir de un modo arbitrario en un ámbito de la vida pública urbana tan sensible como la fiscalidad. En ambos casos, la arbitrariedad con la que actuó, o pretendió actuar, el regimiento no persiguió intereses claros y específicos de los dominantes sino que se ajustó a una defensa directa de los intereses de la comunidad urbana.

Como en otras ocasiones, que jalonan la cotidianeidad de las decisiones regimentales a lo largo del siglo, estas dos medidas se vincularon y encontraron su justificación en la defensa de políticas de pro comunal, es decir en la activa persecución del bien común. Como hemos tenido ocasión de observar en este estudio, a través de estos procedimientos de actuación política, el corazón de la dominación ponía en ejecución medidas de incorporación a la dominación de los dominados en general (como concepto abstracto que abarcaba a un amplio espectro de la estructura social) y de segmentos o grupos específicos de dichos dominados en particular ${ }^{28}$. De este modo, y mediante la generación de niveles razonables de paz social en la ciudad, los dominantes se aseguraban un no menos razonable nivel de disfrute pacífico de las posiciones privilegiadas de poder

${ }^{27}$ AMC, LLAA, leg. 185, exp. 5, fols. 1v-2v.

${ }^{28}$ De este tipo de estrategias se ha ocupado MONSALVO ANTÓN, J.M. en «La participación política de los pecheros en los municipios castellanos de la Baja Edad Media. Aspectos organizativos», en Studia Historica. Historia Medieval, VII (1989), pp. 37-93. 
que ocupaban. Una seguridad construida sobre la base de una imagen política, de una percepción de su actuación política determinada por su defensa de la comunidad, y no sólo o no siempre de sus intereses particulares.

Sin embargo, y al mismo tiempo que los dominantes, mediante estas políticas de bien común, «atraían» hacia la dominación a segmentos y grupos dominados, la misma concepción e implementación de estas políticas de bien común reducía, al menos en teoría si no también en la práctica, la capacidad de «libre» actuación política de los dominantes, forzados, como hemos visto, a aplicar aquéllas en las circunstancias que se ajustaban a los modelos de definición de las políticas de bien común enunciados por los propios dominantes. Esta limitación «positiva» de la capacidad de actuación de los dominantes también favoreció la generación de una cierta percepción, igualmente positiva, de ellos por parte de los dominados, al centrarse la valoración de su actuación política en la persecución de objetivos comunitarios. Desde luego, esta evaluación también afectó positivamente al aseguramiento de aquellos niveles de paz social.

Así, la reducción y permanente enunciado de estas acciones políticas en el seno de un marco conceptual definido por las políticas de bien común, facilitó la puesta en práctica de procesos tácitos de categorización, compartidos de manera positiva por los diversos sectores de la estructura social, de estas políticas, de los gestores de aquéllas (los dominantes) y, por extensión, de la gestión política suprema (la dominación) ${ }^{29}$. De esta manera, a través de estas prácticas no sólo se alcanzó una cierta paz social sino también un cierto nivel de legitimación de la dominación, objetivo último buscado por los dominantes. En cierto sentido, la implementación de las políticas de bien común se transformaba en objetivo particular de la dominación.

\footnotetext{
29 Sobre la efectividad de estos procesos de categorización, la generación de las consiguientes percepciones compartidas y la construcción y reconstrucción de modelos de organización y cohesión grupales y de producción de respuestas colectivas a esos estímulos, véase TAJFEL, H., «Social Stereotypes and Social Groups», en TURNER, J.C. y GILES, H. (eds.), Intergroup Behaviour, Basil Blackwell, Oxford, 1981, pp. 144-167.
} 